\title{
Special Section on Action Research
}

\section{Reflections of a Social Justice Counselor in Training: What Action Research Has Meant to Me}

\author{
Amy Johnson Howton \\ University of Cincinnati
}

\begin{abstract}
This article details my professional identity development as a social justice counselor and the role that action research has played in supporting my development. As an action researcher and social justice counselor, I have come to understand my location in the larger field of counseling as an "outsider-within" (Collins, 1990), positioned in the "borderlands" (Anzaldua, 1987) of the field. Action research helped me to understand how this positioning creates both opportunity and challenge for me personally and professionally. I describe three key lessons learned from my work as an action researcher that translate to my envisioned role as a counselor: 1) the impact of power and privilege on relationships 2) the significance of the process itself, and finally, 3) change is messy. I argue that my own struggle to secure for myself a sense of place and legitimacy within the field of counseling reflects a similar struggle to that being experienced by social justice counseling in general within the larger field of counseling.
\end{abstract}

Keywords. social justice, action research, identity development, counselor 


\section{Introduction: My Journey}

I am writing this from what I now clearly understand to be the "borderlands" (Anzaldua, 1987) of the field of counseling. It has taken me a long time to find my voice from this place, where I feel always like both an outsider to the counseling field and an insider, at the same time. For example, my work as a university Student Affairs administrator requires me to regularly articulate the boundaries of my job to the students with whom I work. Because I do not do traditional (read clinical) counseling in this role, I find myself needing to say - nearly every day - "I am not a counselor." And yet, as a doctoral candidate in Counselor Education, I very much am. This paradox illustrates an ongoing tension that I have experienced in my counselor identity development: trying to secure a place to legitimately claim the identity of counselor. For me, this has meant reconciling and embracing this both/and dichotomous nature of my professional identity so that I can effectively push the boundaries of the traditional counselor role to create a space I can occupy as what I understand to be a social justice counselor. This process has been a challenging and stimulating one, which I argue, like all things personal, reflects the larger political state of the social justice counseling field.

There has been a crescendo in the call for an expansion in counselors' roles (Speight \& Vera, 2008; Toporek, Gerstein, Fouad, Roysircar, \& Isreal, 2006; Vera \& Speight, 2007) and increased attention to change strategies that focus on organizational/social transformation (Bemak \& Chung, 2008; D’Andrea \& Heckman, 2008; Evans, Hanlin, \& Prilleltensky, 2007; Greenleaf \& Williams, 2009; Prilleltensky, Dokecki, Frienden, \& Wang, 2007; Vera \& Speight, 2003). Unfortunately, the field continues to struggle to put into practice its theoretical social justice commitment and has been criticized for falling short of successfully doing so. (Baluch, Pieterse, \& Bolden, 2004; Bemak, 1998; Goodman, Liang, Weintraub, Helms, \& Latta, 2004; Pieterse, 2009; Prilleltensky, 1997; Vera \& Speight, 2003) As a social justice counselor in training, I feel the growing pains of expanding our traditional counselor roles - both on a personal and institutional level.

I came to the field of counseling looking for answers. Trained in Women's Studies, I gained a strong theoretical foundation for understanding intersectional systems of oppression. I had read, thought, and written a lot about the whats and whys of the state of the world, and how critical it is to create and employ effective strategies of change. Unfortunately, I had not gained the skills to actually realize these strategies of change. For this, I turned to the field of counseling.

I was particularly drawn to my current graduate program's "Ecological Counseling" (EC) orientation. This orientation spoke to my Women's Studies background, and I was excited to learn how to make a difference - not only in an individual's life but also in the multiple, ecological levels affecting it. Frankly, I soon learned that what was in theory, was not so much in practice. Even the "ecological" interventions were focused on the individual and micro-levels: contacting a student's school, working with a case manager to provide wrap-around services, and connecting a family with community resources. I did not feel like I was learning to address larger systemic problems or to facilitate positive change on multiple ecological levels. At times, 
I seriously questioned my calling as a counselor, but also was compelled to push the boundaries of the field and to claim a new sort of professional identity that more accurately reflected what I understood to be ecological and social justice counseling: working to address systemic and structural inequality.

I graduated from my Master's program realizing that I could not occupy the traditional role of counselor. I was thrilled to find a job in a campus-based Women's Center. In my role as Sexual Assault Response Coordinator, I was charged to provide advocacy to victims of sexual assault, intimate partner violence, and stalking but also to coordinate the larger university response to these crimes. I trained first responders, developed prevention and education programs, and advocated for better systems of response with campus police, campus disciplinary processes, and healthcare providers. Because the Women's Center itself is explicitly committed to creating change on multiple levels (individual, institutional, social), I had the opportunity and challenge to employ my counseling skills in a variety of contexts.

Although I realized that I was using my skills as a counselor, at the time, I could not define my work as counseling. I had yet to find reflections of myself in the field among those counselors I met through supervision and other professional networking events; I felt that the work I was doing in the Women's Center was not recognized by others in the field as legitimately counseling. Professionally, I identified as an "advocate." My professional identity of an advocate empowered me to position myself as both a counselor and not a counselor, simultaneously.

Despite some ambivalence, after a couple of years, I enrolled in the Counselor Education doctoral program. From the outset, I felt out of place, like an outsider; I was the only member of my cohort not practicing clinical counseling. I found it difficult to relate to my fellow counselors' work in their roles as counselors. Further, my interest in learning how to facilitate organizational, institutional, and social change, which I understood to be inherent in the work of social justice counseling, seemed not to be shared with my peers. I decided to leave the program. After a year, my program advisor reached out to me and encouraged me to reconsider; after serious consideration, I decided to give it one more try.

I am fortunate I did. I'm not sure why I experienced the program differently the second time around, but I did. As I immersed myself in the counseling literature, the cry among social justice counselors to rethink our profession and our role as counselors deeply resonated with me, and I began to reconsider myself a counselor. Not only did our readings focus on the whys of ecological counseling, we explored ways of actually doing the work - which is what I had been waiting for: the hows. In one seminar course, my cohort was charged with working with a local community mental health agency seeking to make organizational change through the adoption of an ecological counseling orientation. Doing this work in the context of a counselor education program felt validating and legitimized the work as counseling. At the same time, as we struggled with how to facilitate the organizational change, I also was struck by the very limited number of evidenced counseling strategies employed by counselors to facilitate ecological change. Continuously, I receive mixed messages from the field in terms of "what counts" as counseling. On one hand, there is an increased call for ecological and social justice counseling; on the other, counseling interventions highlighted in the field's professional journals 
and conferences do not exemplify organizational, institutional, or social change processes. As I noted in my research journal,

While validated and supported by my advisor, I often feel out of place with my cohort. The only one not practicing clinically, I sometimes question my interests and work as 'real,' 'valid' counseling. Intellectually, I could argue this point. Emotionally, I wonder. I don't see reflections of myself in the field. (personal journal, September, 2008)

This precarious situation of being simultaneously within a community and also positioned outside of it is one faced by many who occupy a marginalized social situation. For example, Collins (1990) coined the term "outsider-within" to describe this positionality. Later, in reflecting on the term's use and meaning, she wrote:

Over time, what began initially as a personal search to come to terms with my own individual experiences of disempowerment within intersecting power relations of race, gender, and social class led me to wonder whether African American women as a group occupied a comparable collective social location. (Collins, 1999, p. 85)

Now, I found myself occupying this space professionally, feeling on the margins of my field as a social justice counselor. My personal feelings prompted me to also think, as Collins had, about the collective social location of social justice counselors within the larger field of counseling. My advisor suggested that as I continued to search for other ways of doing and being in the field of counseling, I enrolled in a year-long Action Research sequence. I took her advice. Quite simply, it changed my life.

\section{Action Research: My Answer?}

As I began to read and learn about action research (AR), I immediately felt like I was "home." Shared principles, theoretical orientations, and ultimate goals closely align the social justice counseling and AR disciplines. Making these connections was important for me in that it provided me a new framework from which to conceive of counseling. Again, returning to my research journal, I reflected,

Really beginning to conceptualize AR as EC, finding myself applying the readings and my own interpretations to our class project and questions I've had about counseling. So many of these questions are the same so that in a sense research becomes equated to counseling/intervention. Makes sense in that for each an "expert" collects data, gathers information, develops and implements interventions and then summarizes findings. Concerns about epistemology, ontology, methodology translate easily between these "two" "fields," perhaps due to the way in which power has been constructed, assumed, and reinforced. Both $A R$ and EC turn this power on its head, deconstructing traditional practices to question the justness - and effectiveness - in not engaging participants/clients in their own change process. From the initial stages of problem identification, to development of research question and methodology, to other, ongoing decisions are recommended to be collaboratively for and with those affected by the 
work. According to these frameworks, efforts are made to lessen the divide between us/them, to challenge its very dualistic opposition. Trust is key. (personal journal, October, 2008)

For me, AR became the bridge between my two, seemingly oppositional identities of "outsider" and "insider," helping me to translate the theoretical to the practical. Action research provided me with a practical model, both methodologically and philosophically, by which to facilitate change and do counseling. The history of AR and its extensive body of literature gifted me with practical examples of how AR - and therefore, social justice counseling - is employed in creating change on multiple systemic levels. I was not alone. In fact, I realized that the feelings resulting from an "outsider-within" positionality is experienced by most action researchers. As Brydon-Miller, Greenwood, and Maguire (2003) observed, "From the descriptions of the journey to action research...it appears that many of us have one thing in common - our profound dissatisfaction with where we were" (p. 12). Action research helped me realize that I could - and should - be BOTH a counselor AND not really a counselor in order for me to fully embrace and enact what social justice counseling means to me. That is, to create change, one must be both/and: both inside the system and outside of it. So, to effectively push the boundaries of our field, my identity as a professional counselor who has struggled with feeling marginalized and outside the field positions me and others who might have experienced these feelings, in a key position to create positive change in the field. Action research helped me see this. I had found my answer.

I feel validated and confident that I am where I need to be in my own scholarship. Many things have come together for me through action research - questions, concerns, interests. Although I'm not $100 \%$ certain of where I fit within my field, I am sure that I am where I belong. Maybe - I suspect this to be true - I would never, could never, feel like I fit in any one discipline. I exist in my scholarship on/in the boundaries and will be positioned necessarily, as always insider/outsider. While I choose this and embrace this position, at times it makes me feel uncomfortable and question my own legitimacy as scholar/counselor/educator. I suppose this is just where I should be: critically aware of my position. (personal journal, January, 2009)

\section{Lessons Learned}

Over the past two years, I have learned a lot from AR, and those lessons have greatly informed my construction of my professional identity as a counselor, my work, and the way in which I do it. Yet, it is important not to romanticize AR, and for me, it has been deeply upsetting to experience the pitfalls of the practice. At times, I questioned the very possibility of the methodology. These moments, while frustrating provide significant opportunity to grow and change. I appreciate that this is what the practice of action research most fully promises: the opportunity to critically learn and make change - not only in terms of the research (and counseling) problem itself but personally, as a researcher (and counselor). 


\section{Location, location, location: power and privilege}

Central to action research is the notion that research should be conducted with participants rather than on them, recognizing participants as subjects as opposed to objects. Reason and Bradbury's (2001) definition of action research evidences this concept:

Action research is a participatory, democratic process concerned with developing practical knowing in the pursuit of worthwhile human purposes, grounded in a participatory worldview which we believe is emerging at this historical moment. It seeks to bring together action and reflection, theory and practice, in participation with others, in the pursuit of practical solutions to issues of pressing concern to people, and more generally the flourishing of individual persons and their communities. (p.1)

What defines action research is its emphasis on the value of relationships among participants, acknowledging all as knowers and as such, positioned with power. This epistemological framework directly opposes more traditional, positivist forms of research in which the researcher is positioned as expert knower and the participants are framed as objects on which to study. As Brydon-Miller et al. (2003) write, "We embrace the notion of knowledge as socially constructed and recognizing that all research is embedded within a system of values and promotes some model of human interaction, we commit ourselves to a form of research that challenges unjust and undemocratic economic, social and political systems and practices" ( $p$. 11). Rather than trying to neutralize these relationships in order to seek the argued one, objective truth, AR aims to foster these relationships in order to make sustained change.

Deconstructing the traditional relationship between researcher and participant, the researcher is called to always be mindful of the inherent power and privilege that comes with both the positionality of researcher and (also) each participant. Ideally, the process of AR should be empowering for all participating in it, but this empowerment cannot be realized if the relationship is not attended to, the distinct positionalities acknowledged and the power dynamics continuously made explicit.

I knew that I wanted to undertake the challenge of conducting an insider action research (IAR) study for my dissertation; considering how to do this ethically and with integrity reinforced this lesson for me over and over. As an insider to my organization, there were many things to consider related to positionality in undertaking IAR, and attending to these relationships was critical. For example, how would I ensure members voluntarily participated in the study? What if my study produced "bad news" for my organization? How might my various relationships with participants (as friends, colleagues, supervisor, supervisee) impact the study? Who would own the data? At times, the ethical challenges were overwhelming and yet, as Moore (2007) aptly put it, I was "tempted" by the prospects. I felt strongly that an IAR project could bring about positive change for me, my organization, and the participants. Secondly, I was and am convinced, that when done with care, AR has the potential to build relationships and community among participants; I wanted my organization to experience this. Lastly, I needed to do AR as a counselor and define this kind of work as counseling - I saw it as the way for me to secure for myself and others my identity as a counselor. While I believed the process held much 
promise for positive change, I also recognized that there is great risk for coercion, betrayal, and distrust if the power dynamics within and among the participants are not taken into account each step of the research process.

As I began to plan my data collection methods, I had to consider how to create safe ways for all participants to authentically share their voice and experience. Realizing that for some, it would be difficult to do this as a collective due to the power dynamics among all participants (including me), I decided to first interview each participant then present the emerging themes to the group for reaction and further exploration. As I conducted the interviews, these power dynamics at play really struck me. I had thought about these issues extensively throughout the planning of my research but even still, as I sat down with each participant (with each of whom I had a different relationship: colleague, supervisee, supervisor, friend), I realized the degree to which the relationship with the participant impacts the process. With some, the interview context felt awkward and forced; with others, it felt empowering for me, as interviewer, and for the interviewees. For me, I felt like the interview process itself allowed me to engage with certain participants in a way I normally would not, gave me the power - as researcher - to lead the conversation. As for the interviewees, a few explicitly thanked me for valuing their "voice" and inviting them to participate in the study. Some interviewees shared how they felt during the interview ("Oh, this is weird") while others did not. As I worked through the data collection and analysis, I realized that not calling attention to these unique relationships, and how those relationships were differently affected by my newly assumed position of researcher, I would be overlooking a significant piece of the overall AR project and thereby jeopardizing the integrity of the process. Fortunately, many have written with honesty on their experiences doing IAR (Coghlan \& Brannick, 2010; Coghlan \& Holian, 2007; Humphrey, 2007; Moore, 2007), so I had help along the way as I worked to learn and practice this lesson. In some ways, this principle informs the others since it is the relationship between the participants and researcher that is central to the entire AR process.

\section{It's all about the process}

Action research is an ongoing process of iterative cycles. The nature of a process-oriented change strategy has helped me to rethink change interventions altogether. Change is never complete. So, to focus on the product or the outcome is misguided. It is all about the way in which the change strategy is employed. This goes back to the importance and centrality of the relationship between researcher and participant (or counselor and client). The framing of this relationship will inform the entire process and therefore the potentiality for change.

The significance of the role of process became evident for me in a recent action research project employed in my current graduate program faculty. In the fall of 2009, in preparation for a college-wide assessment and strategic planning process, the Counseling Department, along with every other department in the college, was required by the dean to go through a departmental assessment process. The dean selected an external consultation group to facilitate an action evaluation process. Action evaluation is a mode of cooperative inquiry grounded in action research and framed by conflict engagement and organizational learning (Rothman \& Friedman, 2001; Rothman, Friedman, \& Withers, 2006). Guiding principles to this form of evaluation include participatory action, reflexive dialogue, process-centered, and conflict 
engagement. The action evaluation process aimed to collaboratively identify and implement departmental goals. The department had been going through significant transition, with a new Program Director, the acquisition of a new baccalaureate program, and advocating a move from an Ed.D. to a Ph.D program. As a result of this transition, the action evaluation consultant noted the department faculty to be experiencing feelings of "despair and stress" (J. Rothman, personal communication, May 13, 2009).

According to the consultant, the Counseling Program had significant buy-in to the action evaluation process from the beginning. (J. Rothman, personal communication, May 12, 2009) He noted that there was "internal resonance" with the philosophy of action evaluation; theoretically, the program's Ecological Counseling orientation and the theoretical framework of action evaluation itself closely aligned. Common principles of the two included: shared power, collaboration, participatory meaning-making, iterative cycles, and contextual understanding. One particularly significant tenet that both this form of evaluation and the program itself share is the emphasis on meaning-making through reflexive dialogue. Essentially, both value process.

Because of the philosophical alignment, using action evaluation as a means of goal planning and assessment made sense to the program. The faculty appreciated what this process could mean to the program - both in terms of goal planning and team building. As one faculty member noted,

This process definitely helps the faculty to understand each better at a different level, and has benefited the program as well. The process also helps the program develop a strategic plan that everyone endorses. It meant that it becomes clarified that we share many goals. (Participant A, personal communication, May 20, 2009)

An additional faculty member agreed to the significance of the participatory nature of the action evaluation process.

Although we had on a number of past occasions pursued attempts to establish counseling program action plans and strategies, my sense is that the process we accomplished this fall was much more interactive and personally involving. As a result of the personal investment accomplished through our discussions, I'm certain the product was better. Also, I'm betting that we will find we are more committed to implement our program's plans after having completed the planning together in this way. Personally, I know that I feel more dedicated to the accomplishment of the goals and directions we set than I might have been with a less interactive process. (Participant B, personal communication, May 11, 2009)

Interestingly, while the process itself was clearly significant to the faculty members in terms of how they experienced the overall evaluation and what they expected to gain from it, one faculty member also noted the importance of sustaining the process after the action evaluation itself had completed (at least as far as the dean was concerned). The faculty member observed,

Our program has always had a problem sustaining energy for any project. We are a faculty of loners working in the University of Management by Crisis. Even if there were 
no interruptions, we meet weekly for staff meeting and then don't talk to one another in between. We have no sustained communications via email or phone. We don't do lunch. In our separateness, our collective energy dies and we drift toward entropy... We have little or no sustaining infrastructure for the program. Routine maintenance is not routine. When a student, a faculty member, staff, or administration complains about something, we try to respond quickly and make a fix, but no plans are made for preventive maintenance of the program's infrastructure. (Participant C, personal communication, May 10, 2009)

Central to the success of any action research is the process or the way in which it is employed; the sustainability of that process is central to the achievement of ultimate goals. This sounds easy but as attested to by the above-mentioned faculty member, many times external and internal factors preclude the process, making it nearly impossible to sustain the momentum necessary to bring to fruition the action research plans.

\section{Change is messy}

It seems a mantra among action researchers is "AR is messy." What is the mess? The mess is the nature of the process itself; the fact that by positioning all participants as knowers and by trusting that meaning reveals itself organically, that unplanned things will inevitably happen. Using this methodology, the researcher can carefully plan and care for the process but ultimately, the researcher is not - and cannot be - in complete control of the process. In this way, the process is unpredictable, complicated, and "messy."

Frankly, I have at times experienced this "messiness" as an excuse for us - justifying behaviors that are not productive, allowing us to neglect things we should address, and permitting us to be lazy. At the same time, I do believe the "mess" is a necessary and critical aspect of AR. Inherent in the mess is the notion that there is no one right way. There is no one expert. There is no Truth. It is not about finding the answer or the solution but raising the questions. Again, it is not about the product but the process. The trick in AR is attending to the mess with very careful and critical eyes - each moment of each iterative cycle. Just because the process is messy and full of uncertainty should not in any way justify a lackadaisical methodology; in fact, because of its messy nature, AR demands more energy and attention. It is exhausting.

To make meaning of the mess and to ensure that the mess is well navigated and ethical, there are two important things to keep in mind: 1) conflict should not be avoided and 2) honest and clear communication is key. These two principles are particularly critical to AR because of the emphasis this methodology places on the relationships between and among researcher and participant(s). AR is unique in the way in which this relationship is constructed and reinforced throughout the research process, and thus there are unique demands in attending to these relationships and the process. In fact, the relationship-building aspect of $A R$ is a defining, ultimate goal of the entire research process. Therefore, to foster truly authentic, collaborative relationships, hence a truly authentic, collaborative AR process, communication, and conflictengagement are critical. 
For example, in the action evaluation process that the Counseling Department experienced, conflict engagement was a central principle, viewed by the evaluation team as valuable in providing an opportunity to clarify purpose, expectations, and direction (J. Rothman, personal communication, May 10, 2009). Rather than avoiding the tension, underlying assumptions were continuously challenged and respectfully explored, making the implicit explicit. Taking time to understand participants' worldviews and values, building trust and relationships, provides the necessary foundation for a process that is authentic and genuinely reflects the values of the participants; after all, the process belongs to the participants. Therefore, in the context of action research, conflict engagement means taking the time and care to fully explore participants' genuine feelings and values. At times, this can be difficult, but when done with care, can be very rewarding and is a critical component of fostering a fully participatory and inclusive process - and ultimately, meaningful product. If the trust and relationship building is developed, conflict engagement should be experienced as respectful and not necessarily negative or judgmental. Rather, it is a way in which to include all voices and be truly participatory in nature. It is noteworthy that not one of the Counseling faculty members recalled any "conflict" per se in the evaluation process. Perhaps this lack of recall reflects different understandings of what constitutes "conflict." Possibly, participants did not experience conflict as it is commonly understood (i.e. negative and hurtful) but rather as an intentional catalyst for further progress.

The second principle to keep in mind when attending to the "mess" of AR is honest and clear communication - not only with and among participants but with oneself as researcher/participant as well. It is imperative to be honest with oneself about every decision made in the research process, to be self-critical. This critical lens enables the researcher to create the distance from the project necessary to adequately attend to the process. Herr and Anderson (2005) speak to this charge to action researchers:

We suggest that our obligation as researchers is to interrogate our multiple positionalities in relationship to the question under study. Our sense is that in making explicit the tensions we experience as researchers in our varying roles and statuses, we have the possibility of crafting uniquely complex understandings of the research question. In addition, we hope to avoid the blind spots that come with unexamined beliefs. (p. 44)

To meet this challenge, I maintain an extensive research journal, documenting my questions, decision-making processes, and ongoing meaning-making. My journaling creates and maintains the "outsider-within" status I occupy as (an) inside-action researcher, a space in which I can critically reflect on what it means for me to be both researcher and participant and the impact that status has on my project.

Clear and honest communication with and among participants is also key. Honest communication requires explicitly articulating the research agenda(s). Why are you interested in this research? What do you personally hope to gain? What is in it for you? These are hard but important questions to consider and articulate. And although action researchers and counselors in general like to conceive of themselves as benevolent and self-sacrificing, as 
"helpers," there is always an agenda. Being honest with ourselves and other co-researchers about why we're doing what we're doing is necessary to create a process with integrity.

Clear communication seems basic, and yet it can also be challenging to achieve. During an action research project undertaken by my year-long action research class, my classmates and I learned the hard way the importance of maintaining clear communication. Excited by the promise of technology, we employed a variety of technologies to help us in the planning and implementation of our action research project: Wikis, Blackboard, email, discussion boards. Frankly, it was a nightmare. There was a lot of communication. Not much of it was clear. Documents were lost, efforts duplicated, and voices silenced and dismissed. It was a mess. And not the intentional, productive kind of mess that AR aims to be! Our communication was unclear and unproductive. It took some time for us collectively to find the courage to give up all of our seductive technologies in order to save our project, and even then, it might have been too late for some co-researchers. It is not about quantity of communication, it is the quality.

\section{Concluding Thoughts}

Action research has given me the tools to do the work I am committed to do, as a social justice counselor. It helped me push the boundaries of what I understood to be the typical counselor role and has offered me a new way of conceptualizing what it means to do counseling and be a counselor. Because of my work as an action researcher, I am now able to see myself as a real, legitimate counselor. I have learned that there is a larger, interdisciplinary field in which I belong as a counselor and can join in conversations with others doing similar work, grounded in similar ideology.

And yet, I am continuously reminded that as a social justice counselor who focuses on multisystemic levels of change, I still very much occupy an outsider-within positionality in my own field of counseling. Throughout my dissertation research, Counseling faculty and others have questioned how and why my work constitutes as counseling. For the most part, I welcome these questions and find them validating. I articulate that as a counselor, I seek to create change on multiple levels, and use action research as one methodology to do this. For my dissertation, I engage in an insider-action research project to promote change within my own organization, the UC Women's Center. This answer seems to satisfy some but has not fully satisfied other Counseling faculty. My feelings of being an outsider in the field are valid - how I view counseling is not consistent with how most counselors understand it. What does this mean for me? And for us, as a profession? Interestingly, while I continuously experience this professional identity crisis-of-sorts, the field in general seems to also be experiencing growing pains of its own. Indeed, the personal is political.

The American Counseling Association (ACA), recently underwent a redefinition of counseling, has proposed and accepted this revised definition of counseling: "Counseling is a professional relationship that empowers diverse individuals, families and groups to accomplish mental health, wellness, education and career goals" (American Counseling Association, 2011). Through a democratic process, Counselors for Social Justice (CSJ) overwhelmingly determined not to approve this definition due to a lack of explicit inclusion of "multicultural," "advocacy," and "social justice" in the definition. To disagree with the very basic definition of counseling, 
demonstrates a tension that I believe many social justice counselors feel resulting from our individual and collective location as those that occupy a sort of "outsider" status within the field of counseling - critical of assumptions and always pushing the boundaries of the field to be more focused on systematic oppression.

As a social justice counselor in training, it has become critical for me in my professional development to push the boundaries not only of what it means to be a counselor but of what it means to do counseling. I want to make a difference in my own community of practice. In doing so, it has been the field of action research that has offered me the most practical tools necessary to create reform from within. It is action research that taught me the power of this outsider-within positionality where we embody a position of both/and rather than either/or and the opportunity for transformation that arises from it. Drawing once again on Anzaldua's (1987) notion of borderlands, I feel like I work and exist in the borderlands of the field; as such, parallels can be made between my evolving counselor identity and Anzaldua's "mestiza consciousness." She writes:

The mestiza consciousness is a source of intense pain, its energy comes from continual creative motion that keeps breaking down the unitary aspect of each new paradigm... Because the future depends on the breaking down of paradigms, it depends on the straddling of two or more cultures. By creating a new mythos - that is, a change in the way we perceive reality, the way we see ourselves, and the ways we behave, - la mestiza creates a new consciousness. (p. 102)

I have struggled to make sense of my social justice counselor identity, situating myself in what could be understood to be a borderland in the field. I am convinced that it is because we are positioned as such - in this borderland, as outsiders-within - that we can and will transform the field of counseling.

Contact information/Correspondence:

Amy Johnson Howton

Doctoral Candidate; Counselor Education

University of Cincinnati

Amy.Howton@uc.edu; 513.731.2609 


\section{References}

American Counseling Association (2011). Resources. Retrieved from http://www.counseling.org/Resources/.

Anzaldua, G. (1987). Borderlands/La Frontera: The new Mestiza. San Francisco, CA: Aunt Lute.

Baluch, S., Pieterse, A. L., \& Bolden, M. (2004). Counseling psychology and social justice: Houston, we have a problem. The Counseling Psychologist, 32, 89.

Bemak, F. (1998). Interdisciplinary collaboration for social change: Redefining the counseling profession. In F. T. Sherman \& W. S. Torbert (Eds.). Transforming social inquiry, transforming social action (pp. 279-292). New York: Springer.

Bemak, F. (2008). New professional roles and advocacy strategies for school counselors: A multicultural/social justice perspective to move beyond the nice counselor syndrome. Journal of Counseling and Development, 86, 373-381.

Brydon-Miller, M. (1997). Participatory action research: Psychology and social change. Journal of Social Issues, 53, 657-666.

Brydon-Miller, M., Greenwood, D., Maguire, P. (2003). Why action research? Action Research,1, 9-28.

Coghlan, D. \& Holian, R. (2007) Editorial: Insider action research. Action Research, 5-10.

Coghlan, D., Brannick, T. (2010). Doing action research in your own organization. Los Angeles, CA: Sage Publications.

Collins, P. H. (1990). Black feminist thought: Knowledge, consciousness and the Politics of Empowerment. New York, NY: Routledge.

Collins, P. H. (1999). Reflections on the outsider within. Journal of Career Development, 26(1), 85-88.

D'Andrea, M., Heckman, E. (2008). A 40-year review of multicultural counseling outcome research: Outlining a future research agenda for the multicultural counseling movement. Journal of Counseling and Development. 86, 356-363.

Evans, S., Hanlin, C. Prilleltensky, I. (2007) Blending ameliorative and transformative approaches in human service organizations: A case study. Journal of Community Psychology, 35(3), 329-346. 
Goodman, L. A., Liang, B., Weintraub, S., Helms, J., \& Latta, R. (2004) Warts and all: Personal reflections on social justice in counseling psychology: Reply to Kiselica, Palmer, Thompson and Sherman, and Watts. The Counseling Psychologist, 32, 886-899.

Goodman, L. A., Liang, B., Helms, J., Latta, R., Sparks, E., Weintraub, S. (2004) Training counseling psychologists as social justice agents: Feminist and multicultural principles in action. The Counseling Psychologist, 32, 793-837.

Greenleaf, A. T., Williams, J. (2009). Supporting social justice advocacy: A paradigm shift towards an ecological perspective. Journal for Social Action in Counseling and Psychology. 2(1). 1-14.

Herr, D. \& Anderson, G. (2005). The action research dissertation: A guide for students and faculty. Thousand Oaks, CA: Sage.

Humphrey, C. (2007). Insider-outsider: Activating the hyphen. Action Research, 5, 11-26.

Moore, B. (2007). Original sin and insider research. Action Research, 5, 27-39.

Pieterse, A., Evans, S., Risner-Butner, A, Collins, M., \& Mason, L. (2009). Multicultural competence and social justice training in counseling psychology and counselor education. The Counseling Psychologist, 37, 93-115.

Prilleltensky, I. (1989). Psychology and the status quo. American Psychologist, 44, 795-802.

Prilleltensky, I. (1997). Values, assumptions, and practices: Assessing the moral implications of psychological discourse and action. American Psychologist, 52, 517-535.

Prilleltensky, I., Dokecki, P., Frienden, G., \& Wang, V. (2007). Counseling for wellness and justice: Foundations and ethical dilemmas. In E. Aldarondo (Ed.), Advancing social justice through clinical practice. Mahwah, NJ: Erlbaum, Lawrence and Associates.

Reason, P. \& Bradbury, H. (Eds.) (2001). Handbook of action research: Participative inquiry and practice. London: Sage Publications.

Rothman, J. \& Friedman, V. (2001). Identity, conflict and organizational Learning. In Dierkes, M. (Ed.), Handbook of organizational learning and knowledge, London: Oxford University Press.

Rothman, J., Friedman, V. \& Withers, B. (2006). The power of why: Engaging the goal paradox in program evaluation. American Journal of Evaluation, 272).

Speight, S. \& Vera, E. (2008). Social justice and counseling psychology: A challenge to the profession. In S. Brown \& R. Lent (Eds.), Handbook of counseling psychology. Hoboken, NJ: John Wiley and Sons. 
Toporek, R. L., Gerstein, L., Fouad, N. A., Roysircar, G., \& Israel, T. (Eds.). (2006). Handbook for social justice in counseling psychology: Leadership, vision and action. Thousand Oaks, CA: Sage.

Vera, E. M. \& Speight, S. L. (2003). Multicultural competence, social justice, and counseling psychology: Expanding our roles. The Counseling Psychologist, 31, 253-272.

Vera, E. M. \& Speight, S. L. (2007) Advocacy, outreach and prevention: Integrating social action roles in professional training. In E. Aldarondo (Ed) Advancing social justice through clinical practice (pp. 291-311). New Jersey: Lawrence Erlbaum Associates. 